\title{
28 PLANNING SAFER SUBURBS? THE INFLUENCE OF CHANGE IN THE BUILT ENVIRONMENT ON RESDIENTS' PERCEIVED SAFETY FROM CRIME
}

doi:10.1136/injuryprev-2012-040580a.28

${ }^{1} \mathrm{~S}$ Foster*, ${ }^{1} \mathrm{H}$ Christian, ${ }^{1} \mathrm{~L}$ Wood, ${ }^{2} \mathrm{~B}$ Giles-Corti. ${ }^{1}$ Centre for the Built Environment and Health, University of Western Australia, Australia; ${ }^{2}$ McCaughey Centre, VicHealth Centre for the Promotion of Mental Health and Community Wellbeing, University of Melbourne, Australia

Background Neighbourhoods that promote natural surveillance may support greater feelings of safety; yet few empirical studies have explored the relationship between suburban planning and residents' perceived safety.

Aims/Objectives/Purpose To examine whether changes to the built environment that promote pedestrian movement influence residents' perceived safety from crime.

Methods The RESIDential Environments (RESIDE) study is a longitudinal study of people moving into new neighbourhoods $(n=74)$ in Perth, Western Australia. Participants $(n=1420)$ completed a questionnaire before moving to their new neighbourhood, and again 12 months after relocation. Objective environmental measures were generated at both time points using Geographic Information 
Systems. Linear regression examined the influence of changes to the built and social environments on perceived safety, controlling for individual factors and suburb-level changes in crime.

Results/Outcomes Resident's perceived safety increased after relocation $(p=0.000)$. A decrease in vacant land improved perceived safety ( $p=0.042)$; and perceived improvements in traffic safety and street lighting, and declines in graffiti/vandalism were also determinants of increased perceived safety $(p=0.000)$. Notably, increased social cohesion caused the greatest increase in perceived safety after relocation ( $p=0.000)$.

Significant/Contribution to the Field Changes to the built environment had little impact on perceived safety, however participants typically moved to urban-fringe suburbs where infrastructure was still developing. Residents' changing perceptions were important influences on perceived safety, and community initiatives that improve social cohesion, street lighting and maintenance, and manage traffic may best promote perceived safety. Further follow-up is needed to investigate whether the observed relationships are related to the novelty of moving to a new neighbourhood. 